\title{
Associations between biomarkers and histological assessment in individual animals in a destabilization of the medial meniscus (DMM) model of osteoarthritis (OA)
}

\author{
Seon Young ChOI, Jiheon Rhim, Woo-Jung Han, Hyunjin Park, Jin-Wook NoH, Jungwon Han, Chul-Won Ha
}

From the Department of Health Sciences and Technology, SAIHST, Sungkyunkwan University, Seoul, South Korea

To date, the use of biomarkers for assessing individual severity of osteoarthritis (OA) is limited, and the correlation of histological scores with biomarkers for individual animals in the destabilization of the medial meniscus (DMM) model of OA has not been well investigated. Accordingly, this study investigated how well representative biomarkers in the DMM model reflected specific changes in individual animals.

Rats were randomly divided into the $\mathrm{OA}$ group and the sham group. OA model was established by destabilization of the medial meniscus (DMM). After 2,4,6,8,10 and 12 weeks $(n=14$, each week), the concentrations of CTXII, COMP, C2C, and OC in serum were measured, and cartilage degeneration, osteophytes, and synovial membrane inflammation, typical of $\mathrm{OA}$, were scored using Osteoarthritis Research Society International (OARSI) scoring system. Additionally, the correlation between each biomarker and the specific changes in osteoarthritis was analyzed for individual animals using the Generalized Estimating Equation (GEE).

Statistical analysis showed a low correlation between CTXII and osteophyte score of the medial femur (coefficient $=\mathbf{- 0 . 0 0 8 8}, p=0.0103$ ), COMP and osteophyte score of the medial tibia (coefficient $=$ $\mathbf{- 0 . 0 9 1 1 ,} p=0.0003$ ), and $\mathrm{C} 2 \mathrm{C}$ and synovial membrane inflammation scores of the medial femoral (coefficient $=0.054, p=0.0131$ ).

These results suggest that representative $\mathrm{OA}$ biomarkers in individual animals in the DMM model did not reflect histological scores well.

No benefits or funds were received in support of this study. None of the authors have a conflict of interest.
Keywords : osteoarthritis ; biomarker ; destabilization of the medial meniscus.

\section{INTRODUCTION}

According to previous studies, biomarkers related to osteoarthritis (OA) severity are known $(1,2)$. OA severity has been confirmed by biomarkers and histological score measurements in various animal models, such as anterior cruciate ligament

\footnotetext{
Seon Young Choi ${ }^{1,2}$,

Jiheon Rhim²,

- Woo-Jung Han $^{2}$,

- Hyunjin Park ${ }^{2}$,

- Jin-Wook Noh',

Jungwon $\operatorname{Han}^{3}$,

- Chul-Won $\mathrm{Ha}^{1,2,3}$

${ }^{1}$ Department of Health Sciences and Technology, SAIHST, Sungkyunkwan University, Seoul, South Korea.

${ }^{2}$ Stem Cell \& Regenerative Medicine Research Institute, Samsung Medical Center, Seoul, South Korea.

${ }^{3}$ Department of Orthopedic Surgery, Samsung Medical Center, Sungkyunkwan University School of Medicine, Seoul, South Korea.

Correspondence : Chul-Won Ha, Department of Orthopedic Surgery, Samsung Medical Center, School of Medicine, Sungkyunkwan University, Seoul, 06351, South Korea. Phone : +82-2-3410-0275. Fax : +82-2-3410-0061.

Email : chulwon.ha@gmail.com

- 2021, Acta Orthopædica Belgica.
} 
transection (ACLT), monosodium iodoacetate (MIA), and meniscectomy $(3,4)$. Usually, animals are grouped by weeks, and the OA severity is confirmed through averages or median values of groups (5). However, since the severity of OA within the same period varies by species or individual animals, the identification of OA severity in individual animals is necessary for studies of various therapeutic interventions (6). Previous studies of OA biomarkers mainly measure the histological score and biomarkers in grouped animal models rather than individually. Also, the use of biomarkers to assess OA severity of individual animals is limited (7).

A few studies have identified the correlation between representative biomarkers and histological scores in the OA model $(8,9,10)$. Although there are several studies, such as a previous study that look at the correlation of biomarkers in a rabbit ACLT model (11), a destabilization of the medial meniscus (DMM) biomarker may be reflected differently. That is because OA types caused by the ACLT and DMM differ in mechanism and pathology $(12,13)$.

Recently, among various animal models of osteoarthritis, the DMM model has demonstrated a similar mechanism as that of actual degenerative osteoarthritis and has been widely used as an OA model in mice and rats $(14,15,16)$. However, the correlation between OA severity and representative biomarkers has not been well investigated in the DMM model.

Some of the major changes that OA cause are cartilage degradation, osteophyte formation, and synovial membrane inflammation $(17,18,19)$. But it is not known which biomarker is more prominent in the DMM model. Among the biomarkers used in the study of osteoarthritis are type C-telopeptide of type II collagen (CTX-II), cartilage oligomeric matrix protein (COMP), type II collagen cleavage product $(\mathrm{C} 2 \mathrm{C})$ and osteocalcin $(\mathrm{OC})$ are the most used markers (11). According to the osteoarthritis and biomarker review paper (2), these biomarkers are the most identified biomarkers in the OA studies. It has been reported that there is an association between the serum levels of the CTXII, COMP and radiographic severity in the Knee OA $(20,21,22)$. Serum $\mathrm{C} 2 \mathrm{C}$ has been reported as an effective biomarker for the clinical development of joint disease in animal models $(23,24)$ The OC is a bone formation indicator (25), and the $\mathrm{OC}$ is considered an indicator of bone turnover (26).

Therefore, the purpose of this study was to determine whether representative OA biomarkers measured individually in the DMM model could well reflect the histological score and how well each biomarker could reflect specific changes of the osteoarthritic joint in the DMM model.

\section{MATERIALS AND METHODS}

Wistar rats (12 weeks old, 350-400 g) were obtained from the Orient Bio Inc (Seoul, Korea). These animals were placed in cages with controlled environment ( $12 \mathrm{~h}$ of day light and 12 of darkness, an ambient temperature of $21^{\circ} \mathrm{C}$ ). They were allowed free ad libitum access to water and a standard laboratory pellet diet. All studies were performed after obtaining approval from the Institutional Animal Care and Use Committee of our institution. (Samsung Medical Center, Seoul, Korea. Approval No. 20160727001). The rats were randomly divided into two group, the OA group and the sham group (84 rats per group)

An experimental OA model was created via DMM (14). OA was induced in the left knee joint of each rat. Immediately following OA induction, a single dose of Cefazolin was subcutaneously injected once to prevent joint infection. Ketoprofen was subcutaneously injected to minimize pain.

At two, four, six, eight, ten- and twelve weeks following OA induction, $1 \mathrm{~mL}$ of blood was drawn from the tail vein of each rat $(n=14$, each time point). Blood samples were centrifuged at $1000 \mathrm{x} \mathrm{g}$ for $15 \mathrm{~min}$ at room temperature. The supernatant was collected, aliquoted, and stored at $-80^{\circ} \mathrm{C}$ until use ( $<6$ months). The serum CTX-II concentrations of animals were measured using the rat CTX II ELISA Kit. (Rat CTX-II ELISA Kit, Order No. EKR1754, Nordic Biosite AB, Täby, Sweden). The serum COMP concentrations of animals were measured using the rat COMP ELISA Kit. (Rat COMP ELISA Kit, Order No. EKR924, Nordic Biosite AB, Täby, Sweden). The serum $\mathrm{C} 2 \mathrm{C}$ concentrations of animals were measured using the rat $\mathrm{C} 2 \mathrm{C}$ ELISA Kit. (Rat Collagen Type 2 Cleavage (COL-2AV) ELISA Kit, 

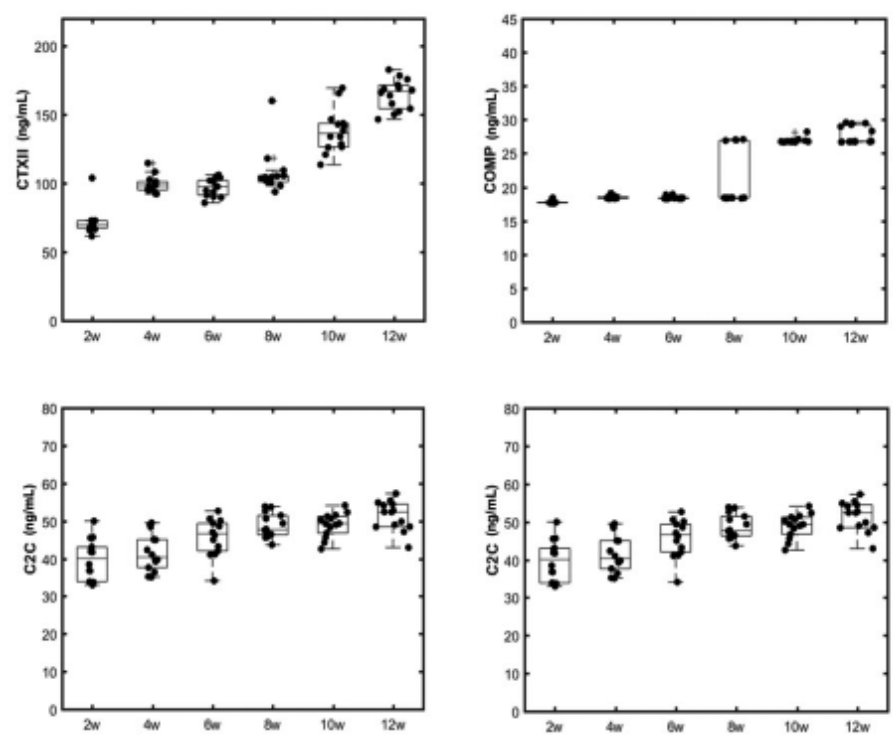

Figure 1. - The concentration of serum CTXII, COMP, C2C, OC in the DMM model at each time point. Results represents MEDIAN \pm IQR (InterQuartile Range) from 14 separate experiments performed in duplicate.

Cat NO. MBS728424, MyBioSource, Inc., CA, USA). The serum OC concentrations of animals were measured using the rat OC ELISA Kit. (Rat Osteocalcin ELISA Kit, Cat NO. MBS728975, MyBioSource, Inc., CA, USA). The analyses were conducted based on the standard methods.

The animals were sacrificed at two, four, six, eight, ten- and twelve-weeks following OA induction ( $n=14$ at each time point). For histological analysis, Safranin-O staining was performed according to the manuals provided by the manufacturer (Nova Ultra Safranin O Stain Kit, IHC World, IW-3011) (27). Histological OA scores were evaluated for slides stained with safranin-O. Using the OARSI scoring system, the OA severity was evaluated according to the cartilage degeneration score, osteophyte score, and synovial membrane inflammation score (cartilage degeneration score, 0-5; osteophyte score, $0-4$; synovial membrane inflammation score, 0-4) (28). All samples were evaluated independently by two observers who were blinded to sample information. Scores were evaluated twice by the observer at intervals of one month.

Intra-observer and Inter-observer agreements were investigated with ICC (Intraclass Correlation
Coefficient) (29). ICC greater than 0.75 indicated a high agreement. A reproducibility analysis was performed for the cartilage degeneration score (medial tibial, medial femoral), osteophyte score (medial tibia, medial femur), and synovial membrane inflammation score (medial tibial, medial femoral).

Generalized Estimating Equation(GEE) was used to analyze the association of each biomarker with each score after adjusting for measurement time, measurement order, and the observer. All analyses were performed using SAS 9.4 (SAS Institute, Cary, NC, USA). Correlations of total score or each specific score with CTXII, COMP, C2C, and OC were analyzed. All tests are both checked and are based on a significance level of 0.05 .

\section{RESULTS}

As shown in figure 1, the median CTXII concentration increased at four weeks as compared to two weeks, unchanged until eight weeks, and gradually increased at 10 and 12 weeks, and individual differences also gradually increased. The median COMP concentration had no change from two through eight weeks, increased at 10 

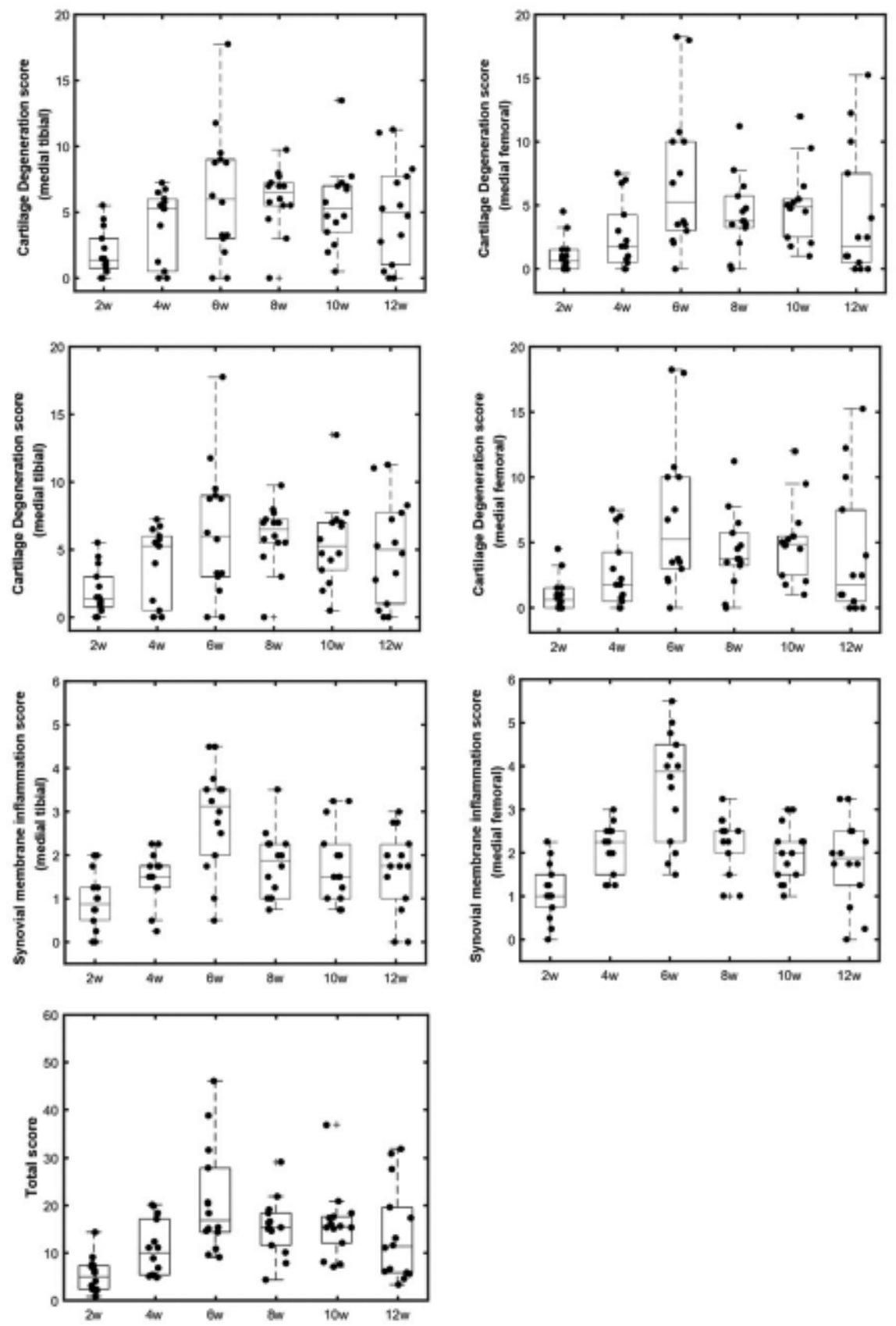

Figure 2. - Histological score of DMM model on each time point. This is a result of analyzing cartilage degeneration, osteophyte formation, and synovial membrane inflammation which are representative changes of OA. Results represent MEDIAN \pm IQR (Interquartile range) from fourteen separate experiments performed in duplicate.

weeks, and maintained at 12 weeks. The median $\mathrm{C} 2 \mathrm{C}$ concentration gradually increased from two to 12 weeks. The median $\mathrm{OC}$ concentration was unchanged from two through six weeks, increased at eight weeks, and unchanged until 12 weeks. At eight through12 weeks, donor variation was increased as compared to two through six weeks (Figure 1). Overall, the biomarkers increased over time 
Table I. - Reproducibility : Intraobserver, Interobserver. The reproducibility ICC values of each parameter for OARSI score were excellent $(\mathrm{ICC}=0.76-0.99)$ except the osteophyte score $(\mathrm{ICC}=0.58$, good $)$.

\begin{tabular}{|c|c|}
\hline ICC & Strength of Agreement \\
\hline$>0.75$ & Excellent \\
\hline $0.75-0.4$ & Agreement between fair and good \\
\hline$<0.4$ & Poor \\
\hline
\end{tabular}

\begin{tabular}{|l|c|c|}
\hline \multirow{2}{*}{ Parameter } & \multicolumn{2}{|c|}{ Test-retest reliability } \\
\cline { 2 - 3 } Cartilage Degeneration score (medial tibial) & Intra-observer & Inter-observer \\
\hline Cartilage Degeneration score (medial femoral) & 0.99 & 0.96 \\
\hline Osteophyte score (medial tibia) & 0.99 & 0.97 \\
\hline Osteophyte score (medial femur) & 0.92 & 0.76 \\
\hline Synovial membrane inflammation score (medial tibial) & 0.89 & 0.58 \\
\hline Synovial membrane inflammation score (medial femoral) & 0.91 & 0.79 \\
\hline
\end{tabular}

after the OA induction. There was no statistically significant change in the sham group for 12 weeks. (sham group data not shown.)

The histology score was measured using the OARSI score system (28). The cartilage degeneration score of the medial tibial increased at four weeks as compared to two weeks and was similar until 12 weeks. The cartilage degeneration score of the medial femoral increased gradually between two and six weeks, and at six through 10 weeks remained similar. The individual differences increased until 12 weeks and was the largest at six weeks.

The osteophyte score of the medial tibia did not change the median value until six weeks, increased gradually at 8 and 10 weeks, and the individual differences increased as well.

The osteophyte score of the medial femur increased between two and six weeks, with no change until 10 weeks. It then increased at 12 weeks. The individual differences increased gradually.

The synovial membrane inflammation score of the medial tibial and medial femoral increased gradually between two through six weeks, then decreased at six weeks and remained similar until 12 weeks. The total score increased gradually over two to six weeks, with the individual differences also increasing, with the greatest variation being at six weeks. The total score median remained similar at six through 10 weeks and then decreased slightly at 12 weeks (Figure 2).

There was no statistically significant change in the sham group for 12 weeks. (Sham group data not shown.)

As a result of analyzing the correlation between the biomarker and the total OARSI score (Table I, II), CTX II (coefficient $=-0.1122, \mathrm{p}$ value $=$ 0.55), COMP (coefficient $=-0.3277, \mathrm{p}$ value $=0.84), \mathrm{C} 2 \mathrm{C}$ (coefficient $=0.0993, \mathrm{p}$ value $=$ 0.68 ), OC (coefficient $=-0.0849, \mathrm{p}$ value $=0.52$ ) showed no statistically significant correlation. There were statistically significant correlations between CTXII and osteophyte score of the medial femur (coefficient $=-0.0088, p=0.01$ ), between COMP and the osteophyte score of the medial tibia (coefficient $=-0.0911, p=0.00$ ), and between C2C and synovial membrane inflammation score of the medial femoral (coefficient $=0.054, p=0.01$ ). However, others showed no significant correlation (Table II.).

\section{DISCUSSION}

Individual evaluation of OA severity using the concentration of biomarkers did not correlate 
Table II. - Correlation analysis between the concentration of serum CTXII, COMP, C2C and OC and histological score (Generalized Estimating Equation (GEE))

\begin{tabular}{|c|c|c|c|c|}
\hline & CTXII & СОМР & $\mathrm{C} 2 \mathrm{C}$ & OC \\
\hline Total score & $\begin{array}{c}\text { coefficient }= \\
-0.1122 \\
\text { p value }=0.0901\end{array}$ & $\begin{array}{l}\text { coefficient }= \\
-0.3277 \mathrm{p} \text { value } \\
\quad=0.5585\end{array}$ & $\begin{array}{c}\text { coefficient }= \\
0.0993 \\
\mathrm{p} \text { value }= \\
0.5041\end{array}$ & $\begin{array}{c}\text { coefficient }= \\
-0.0849 \mathrm{p} \text { value } \\
=0.2914\end{array}$ \\
\hline $\begin{array}{l}\text { Cartilage Degeneration score } \\
\text { (medial tibial) }\end{array}$ & $\begin{array}{c}\text { coefficient }= \\
-0.0179 \\
\mathrm{p} \text { value }= \\
0.5457\end{array}$ & $\begin{array}{l}\text { coefficient }= \\
-0.0405 \mathrm{p} \text { value } \\
=0.8445\end{array}$ & $\begin{array}{c}\text { coefficient }= \\
0.0278 \\
\mathrm{p} \text { value }= \\
0.6781\end{array}$ & $\begin{array}{c}\text { coefficient }= \\
-0.0224 \mathrm{p} \text { value } \\
=0.5179\end{array}$ \\
\hline $\begin{array}{l}\text { Cartilage Degeneration score } \\
\text { (medial femoral) }\end{array}$ & $\begin{array}{l}\text { coefficient }= \\
-0.0541 \mathrm{p} \text { value } \\
=0.0857\end{array}$ & $\begin{array}{c}\text { coefficient }= \\
-0.1727 \mathrm{p} \text { value } \\
=0.5022\end{array}$ & $\begin{array}{c}\text { coefficient }= \\
0.0156 \\
\mathrm{p} \text { value }= \\
0.8361\end{array}$ & $\begin{array}{c}\text { coefficient }= \\
-0.0569 \mathrm{p} \text { value } \\
=0.117\end{array}$ \\
\hline $\begin{array}{l}\text { osteophyte score } \\
\text { (medial tibia) }\end{array}$ & $\begin{array}{c}\text { coefficient }= \\
-0.0057 \mathrm{p} \text { value } \\
=0.2807\end{array}$ & $\begin{array}{c}\text { coefficient }= \\
-0.0911 \mathrm{p} \text { value } \\
=0.0003 * *\end{array}$ & $\begin{array}{c}\text { coefficient }= \\
-0.0081 \\
\text { p value }=0.555\end{array}$ & $\begin{array}{l}\text { coefficient }= \\
0.0047 \mathrm{p} \text { value } \\
\quad=0.5511\end{array}$ \\
\hline $\begin{array}{l}\text { osteophyte score } \\
\text { (medial Femur) }\end{array}$ & $\begin{array}{l}\text { coefficient }= \\
-0.0088 \mathrm{p} \text { value } \\
=0.0103^{*}\end{array}$ & $\begin{array}{c}\text { coefficient }= \\
-0.0395 \mathrm{p} \text { value } \\
=0.1901\end{array}$ & $\begin{array}{c}\text { coefficient }= \\
0.00 \\
\mathrm{p} \text { value }= \\
0.9977\end{array}$ & $\begin{array}{c}\text { coefficient }= \\
0.0024 \\
\mathrm{p} \text { value }= \\
0.6104\end{array}$ \\
\hline $\begin{array}{l}\text { synovial membrane inflammation score } \\
\text { (medial tibial) }\end{array}$ & $\begin{array}{c}\text { coefficient }= \\
-0.0116 \mathrm{p} \text { value } \\
=0.122\end{array}$ & $\begin{array}{c}\text { coefficient }= \\
0.0208 \\
\mathrm{p} \text { value }= \\
0.7267\end{array}$ & $\begin{array}{c}\text { coefficient }= \\
0.0099 \\
\mathrm{p} \text { value }= \\
0.6237\end{array}$ & $\begin{array}{c}\text { coefficient }= \\
0.0027 \\
\mathrm{p} \text { value }= \\
0.7949\end{array}$ \\
\hline $\begin{array}{l}\text { synovial membrane inflammation score } \\
\text { (medial femoral) }\end{array}$ & $\begin{array}{l}\text { coefficient }= \\
-0.0141 \mathrm{p} \text { value } \\
=0.0755\end{array}$ & $\begin{array}{c}\text { coefficient }= \\
0.0045 \\
\mathrm{p} \text { value }= \\
0.9457\end{array}$ & $\begin{array}{c}\text { coefficient }= \\
0.054 \\
\mathrm{p} \text { value }= \\
0.0131 *\end{array}$ & $\begin{array}{c}\text { coefficient }= \\
-0.0051 \mathrm{p} \text { value } \\
=0.5118\end{array}$ \\
\hline
\end{tabular}

Coefficient $=$ estimate value, ${ }^{*}$ p-value $<0.05 * *$ p-value $<0.01$

well with the histological score. In this study, the histological score has special characteristics that require multiple corrections, such as two observers, two repeated measurements, and various weeks, so a statistical analysis was conducted with GEE to confirm the correlation with the biomarker. Usually, most of the OA studies show that the correlation coefficient between the average values of biomarkers and OA severity for each week is high when confirming the degree of correlation between biomarker and OA severity. But this can be confirmed by a Pearson or a Spearman Correlation Analysis, which does not suit the data characteristics. When the correlation was confirmed by using the
Pearson statistical analysis method with the results of this study, the total score and $\mathrm{C} 2 \mathrm{C}$ were found to have a statistically significant correlation with $r$ $=0.848$ and $p=0.033$. The CTXII and osteophyte score of the medial femur $r=0.950, p=0.004$, COMP and osteophyte score of the medial tibia $r$ $=0.846 p=0.034$, COMP and osteophyte score of the medial femur $r=0.897 p=0.015, \mathrm{C} 2 \mathrm{C}$ and cartilage degeneration score of the medial tibial $r$ $=0.854 p=0.030, \mathrm{C} 2 \mathrm{C}$ and cartilage degeneration score of the medial femoral $r=0.838 p=0.037$, OC and osteophyte score of the medial tibia $r=0.876$ $p=0.022, \mathrm{C} 2 \mathrm{C}$ and osteophyte score of the medial femur $r=0.958 p=0.003$. (Suppl Table I.) 
Supplementary Table I. - Correlation analysis between the concentration of serum CTXII, COMP, C2C, OC and histological score (Pearson correlation coefficients).

\begin{tabular}{|c|c|c|c|c|}
\hline & CTXII & СОМР & $\mathrm{C} 2 \mathrm{C}$ & OC \\
\hline Total score & $\begin{array}{c}r=0.683 \\
\mathrm{p} \text { value }=0.135\end{array}$ & $\begin{array}{c}r=0.619 \\
p \text { value }=0.190\end{array}$ & $\begin{array}{c}\mathrm{r}=0.848 \\
\mathrm{p} \text { value }=0.033^{*}\end{array}$ & $\begin{array}{c}r=0.606 \\
p \text { value }=0.202\end{array}$ \\
\hline $\begin{array}{l}\text { Cartilage Degeneration score } \\
\text { (medial tibial) }\end{array}$ & $\begin{array}{c}r=0.687 \\
p \text { value }=0.132\end{array}$ & $\begin{array}{c}\mathrm{r}=0.618 \\
\mathrm{p} \text { value }=0.191\end{array}$ & $\begin{array}{c}\mathrm{r}=0.854 \\
\mathrm{p} \text { value }=0.030^{*}\end{array}$ & $\begin{array}{c}r=0.695 \\
p \text { value }=0.126\end{array}$ \\
\hline $\begin{array}{l}\text { Cartilage Degeneration score } \\
\text { (medial femoral) }\end{array}$ & $\begin{array}{c}r=0.671 \\
\mathrm{p} \text { value }=0.145\end{array}$ & $\begin{array}{c}r=0.598 \\
p \text { value }=0.210\end{array}$ & $\begin{array}{c}\mathrm{r}=0.838 \\
\mathrm{p} \text { value }=0.037^{*}\end{array}$ & $\begin{array}{c}r=0.508 \\
p \text { value }=0.304\end{array}$ \\
\hline $\begin{array}{l}\text { osteophyte score } \\
\text { (medial tibia) }\end{array}$ & $\begin{array}{c}\mathrm{r}=0.810 \\
\mathrm{p} \text { value }=0.051\end{array}$ & $\begin{array}{c}\mathrm{r}=0.897 \\
\mathrm{p} \text { value }=0.015^{*}\end{array}$ & $\begin{array}{c}r=0.785 \\
p \text { value }=0.064\end{array}$ & $\begin{array}{c}\mathrm{r}=0.876 \\
\mathrm{p} \text { value }=0.022 *\end{array}$ \\
\hline $\begin{array}{l}\text { osteophyte score } \\
\text { (medial Femur) }\end{array}$ & $\begin{array}{c}\mathrm{r}=0.950 \\
\mathrm{p} \text { value }=0.004 * *\end{array}$ & $\begin{array}{c}\mathrm{r}=0.846 \\
\mathrm{p} \text { value }=0.034^{*}\end{array}$ & $\begin{array}{c}\mathrm{r}=0.958 \\
\mathrm{p} \text { value }=0.003 * *\end{array}$ & $\begin{array}{c}r=0.700 \\
p \text { value }=0.122\end{array}$ \\
\hline $\begin{array}{l}\text { synovial membrane inflammation score } \\
\text { (medial tibial) }\end{array}$ & $\begin{array}{c}r=0.499 \\
p \text { value }=0.341\end{array}$ & $\begin{array}{c}r=0.444 \\
\mathrm{p} \text { value }=0.377\end{array}$ & $\begin{array}{c}r=0.726 \\
\mathrm{p} \text { value }=0.103\end{array}$ & $\begin{array}{c}r=0.429 \\
\mathrm{p} \text { value }=0.396\end{array}$ \\
\hline $\begin{array}{l}\text { synovial membrane inflammation score } \\
\text { (medial femoral) }\end{array}$ & $\begin{array}{c}r=0.335 \\
p \text { value }=0.516\end{array}$ & $\begin{array}{c}r=0.242 \\
p \text { value }=0.645\end{array}$ & $\begin{array}{c}r=0.534 \\
\mathrm{p} \text { value }=0.275\end{array}$ & $\begin{array}{c}r=0.252 \\
\mathrm{p} \text { value }=0.360\end{array}$ \\
\hline
\end{tabular}

$\mathrm{r}=$ Pearson's r, * p-value $<0.05 * *$ p-value $<0.01$

A significant correlation between a biomarker and OA severity was not found due to individual variations of $\mathrm{OA}$ severity. In this study, the concentration of biomarkers increased with the number of weeks, and the variation between individuals is not large. In contrast, the histological score is not a pattern that continuously increases over the weeks, and individual variations increase weekly. Although the DMM model has the most similar mechanism to an actual degenerative osteoarthritis, Kim et al. have reported that the DMM model has some individual variations(16). Therefore, it is very important to find markers of OA severity that can best reflect individual variations in the DMM model of OA in future studies. The results of this study show that osteoarthritis does not progress consistently in the DMM model, and individual animals have a variation. Therefore, it is not appropriate to judge OA severity by the number of weeks. It is not appropriate to compare it in different individuals because those differences increase as the number of weeks increases. Previous studies have focused on the correlation between OA severity and biomarkers in groups. Hence, individual differences were not accounted for as a possible issue that could arise (e.g., restriction in individual therapeutic intervention) $(7,30)$.

In this study, only males were used to induce the DMM model. According to a previous study, in the cases of DMM models, there was a statistically significant increase in OA severity in males following DMM surgery, depending upon the number of weeks that had passed. But it was reported that females showed no statistically significant increase (31). Therefore, the purpose of this study was to determine the correlation between biomarkers by measuring the OA severity. Therefore, only used a male DMM model.

Synovial membrane inflammation is also one of the major changes in OA, and the direct biomarker associated with this was not measured in this study. Biomarkers were selected by referring to the "The number of publications on the individual biomarkers is an estimate provided by pivotal search PubMed" list in the OA biomarker review paper. CTX-II and COMP have been tested in over 50 different studies. OC and $\mathrm{C} 2 \mathrm{C}$ have been tested in more than 20 studies. Thus, these four markers were selected in this study. Jung et al. have reported that COMP is correlated with synovium (32). COMP is 
a glycoprotein secreted mainly from chondrocytes and synovial cells and is an indicator reflecting the metabolic state of the cartilage. Therefore, it can be analyzed with synovial biomarkers based on the COMP results of this study $(33,34)$. In addition, since synovial membrane inflammation is known to increase with increasing OA severity, it is considered to be predictable through OA severity and related biomarkers.

Evaluation of OA severity did not include experiments related to pain or function. Commonly, pain and function in OA are affected by histological OA severity, so when analyzing pain and function, it is expected that the results will not be significantly different from the results of this study (35). Also, it is difficult to study pain and function in these animals. Such studies in small animals are especially difficult and inaccurate.

\section{CONCLUSION}

In the DMM model, when the serum concentrations of the four biomarkers of OA representing CTXII, COMP, C2C, and OC were measured, and histological analysis of specific changes in the osteoarthritic joint was analyzed, there was no significant correlation between the total score and biomarkers. There were statistically significant correlations between CTXII and osteophyte score of the medial femur (coefficient $=-0.0088 p=$ 0.01), between COMP and osteophyte score of the medial tibia (coefficient $=-0.0911 p=0.00$ ), and between $\mathrm{C} 2 \mathrm{C}$ and synovial membrane inflammation score of the medial femoral (coefficient $=0.054 p=$ $0.01)$. These results indicate that the representative biomarkers of the OA did not reflect the histological score of individual animals well.

\section{REFERENCES}

1. Legrand CB, Lambert CJ, Comblain FV, Sanchez C, Henrotin YE. Review of Soluble Biomarkers of Osteoarthritis : Lessons From Animal Models. Cartilage. 2017 ; 8(3) : 211-33.

2. Bay-Jensen A, Reker D, Kjelgaard-Petersen C, et al. Osteoarthritis year in review 2015 : soluble biomarkers and the BIPED criteria. Osteoarthritis Cartilage. 2016 ; 24(1) : 9-20.
3. Kuyinu EL, Narayanan G, Nair LS, Laurencin CT. Animal models of osteoarthritis: classification, update, and measurement of outcomes. J Orthop Surg Res. 2016 ; 11(1) : 1-27.

4. Watt FE. Osteoarthritis biomarkers: year in review. Osteoarthritis cartilage. $2018 ; 26(3): 312-8$.

5. Bendele AM. Animal models of osteoarthritis. J Musculoskelet Neuronal Interact. $2001 ; 1(4)$ : 363-76.

6. Iijima H, Aoyama T, Ito A, et al.Destabilization of the medial meniscus leads to subchondral bone defects and site-specific cartilage degeneration in an experimental rat model. Osteoarthritis cartilage. 2014 ; 22(7) : 1036-43.

7. Van Spil W, DeGroot J, Lems W, Oostveen J, Lafeber FP. Serum and urinary biochemical markers for knee and hip-osteoarthritis: a systematic review applying the consensus BIPED criteria. Osteoarthritis cartilage. 2010 ; 18(5) : 605-12.

8. Ma T, Zhang Z, Song $X$, et al. Combined detection of COMP and CS846 biomarkers in experimental rat osteoarthritis : a potential approach for assessment and diagnosis of osteoarthritis. J Orthop Surg Res. 2018 ; 13(1) : 1-9.

9. de Visser HM, Sanchez C, Mastbergen SC, et al. Fib33 as a biomarker for osteoarthritis in a rat model with metabolic dysregulation. Cartilage. 2019 ; 10(3) : 329-34.

10. Legrand CB, Lambert CJ, Comblain FV, Sanchez C, Henrotin YE. Review of soluble biomarkers of osteoarthritis: lessons from animal models. Cartilage. $2017 ; 8(3): 211-33$.

11. Bai B, Li Y. Combined detection of serum CTX-II and COMP concentrations in osteoarthritis model rabbits : an effective technique for early diagnosis and estimation of disease severity. J Orthop Surg Res. 2016 ; 11(1) : 1-7.

12. Holyoak DT, Tian YF, van der Meulen MC, Singh A. Osteoarthritis : pathology, mouse models, and nanoparticle injectable systems for targeted treatment. Ann Biomed Eng. 2016 ; 44(6) : 2062-75.

13. Little CB, Zaki S. What constitutes an "animal model of osteoarthritis" - the need for consensus? Osteoarthritis cartilage. $2012 ; 20(4): 261-7$.

14. Glasson SS, Blanchet T, Morris EA. The surgical destabilization of the medial meniscus (DMM) model of osteoarthritis in the $129 / \mathrm{SvEv}$ mouse. Osteoarthritis Cartilage. 2007 ; 15(9) : 1061-9.

15. Kamekura S, Hoshi K, Shimoaka T, et al. Osteoarthritis development in novel experimental mouse models induced by knee joint instability. Osteoarthritis Cartilage. 2005 ; 13(7) : 632-41.

16. Kim B, Kim DW, Kim S, et al. Establishment of a reliable and reproducible murine osteoarthritis model. Osteoarthritis Cartilage. 2013 ; 21(12).

17. Dieppe P. Developments in osteoarthritis. Rheumatology (Oxford). $2011 ; 50(2): 245-7$

18. Loeser RF, Goldring SR, Scanzello CR, Goldring MB. Osteoarthritis : a disease of the joint as an organ. Arthritis Rheum. 2012 Jun ; 64(6) : 1697. 
19. Chen D, Shen J, Zhao W, et al. Osteoarthritis : toward a comprehensive understanding of pathological mechanism. Bone Res. 2017 ; 5(1) : 1-13.

20. Braza-Boïls A, Alcaraz MJ, Ferrándiz ML. Regulation of the inflammatory response by tin protoporphyrin IX in the rat anterior cruciate ligament transection model of osteoarthritis. J Orthop Res. 2011 ; 29(9) : 1375-82.

21. Garnero P, Piperno M, Gineyts E, et al. Cross sectional evaluation of biochemical markers of bone, cartilage, and synovial tissue metabolism in patients with knee osteoarthritis: relations with disease activity and joint damage. Ann Rheum Dis. 2001 ; 60(6) : 619-26.

22. Clark AG, Jordan JM, Vilim V, et al. Serum cartilage oligomeric matrix protein reflects osteoarthritis presence and severity : the Johnston County Osteoarthritis Project. Arthritis Rheum. 1999 Nov ; 42(11) : 2356-64.

23. Vilar JM, Rubio M, Spinella G, et al. Serum collagen Type II cleavage epitope and serum hyaluronic acid as biomarkers for treatment monitoring of dogs with hip osteoarthritis. PLoS One. 2016; 11 : e0149472.

24. Matyas JR, Atley L, Ionescu M, Eyre DR, Poole AR. Analysis of cartilage biomarkers in the early phases of canine experimental osteoarthritis. Arthritis Rheum. 2004 ; $50(2): 543-52$.

25. Nguyen LT, Sharma AR, Chakraborty $C$, et al.Review of prospects of biological fluid biomarkers in osteoarthritis. Int J Mol Sci. $2017 ; 18(3)$ : 601.

26. Ivaska KK, Hentunen TA, Vääräniemi J, et al. Release of intact and fragmented osteocalcin molecules from bone matrix during bone resorption in vitro. J Biol Chem. 2004 ; 279(18) : 18361-9.

27. Zhang X, Wang C, Zhao J, et al. miR-146a facilitates osteoarthritis by regulating cartilage homeostasis via targeting Camk2d and Ppp3r2. Cell Death Dis. 2017 ; 8(4) : e2734-e.

28. Gerwin N, Bendele A, Glasson S, Carlson CS. The OARSI histopathology initiative-recommendations for histological assessments of osteoarthritis in the rat. Osteoarthritis Cartilage. 2010 Oct ; 18 : S24-S34.

29. Pinedo M, Villacorta E, Tapia $\mathbf{C}$, et al. Inter-and intraobserver variability in the echocardiographic evaluation of right ventricular function. Rev Esp Cardiol. $2010 \mathrm{Jul}$; 63(7) : 802-9.

30. Young JJ, Kopansky-Giles D, Ammendolia C. Multimodal non-surgical intervention for individuals with knee osteoarthritis: a retrospective case series. J Can Chiropr Assoc. 2019 ; 63(2) : 92.

31. Ma HL, Blanchet TJ, Peluso D, Hopkins B, Morris EA, Glasson SS. Osteoarthritis severity is sex dependent in a surgical mouse model. Osteoarthritis Cartilage. 2007 ; 15(6) : 695-700.

32. Jung YO, Do JH, Kang HJ, et al. Correlation of sonographic severity with biochemical markers of synovium and cartilage in knee osteoarthritis patients. Clin Exp Rheumatol. 2006 ; 24(3) : 253-9.

33. Garnero P, Rousseau JC, Delmas PD. Molecular basis and clinical use of biochemical markers of bone, cartilage, and synovium in joint diseases. Arthritis Rheum. 2000 ; 43(5) : 953-68.

34. Vilım V, Vytášek R, Olejarova M, et al. Serum cartilage oligomeric matrix protein reflects the presence of clinically diagnosed synovitis in patients with knee osteoarthritis. Osteoarthritis cartilage. 2001 ; 9(7) : 612-8.

35. Piel MJ, Kroin JS, Van Wijnen AJ, Kc R, Im HJ. Pain assessment in animal models of osteoarthritis. Gene. 2014 ; 537(2) : 184-8. 